\title{
Interactions of Combined Haplotypes of Methylenetetrahydrofolate Reductase on Clinical Events in Children with Sickle Cell Disorder
}

\author{
Suprava Patel ${ }^{1}$, Rachita Nanda ${ }^{2}$, Nighat Hussain ${ }^{3}$, Eli Mohapatra ${ }^{4}$, Pradeep Kumar Patra ${ }^{5}$ \\ 1, 2, 4 Department of Biochemistry, All India Institute of Medical Sciences, Raipur, Chhattisgarh, India, ${ }^{3}$ \\ Department of Pathology, All India Institute of Medical Sciences, Raipur, Chhattisgarh, India, ${ }^{5}$ Department of \\ Biochemistry, Pt. Jawaharlal Nehru Memorial Medical College, Raipur, Chhattisgarh, India.
}

\section{ABSTRACT}

\section{BACKGROUND}

Methylenetetrahydrofolate reductase (MTHFR) C677T and A1298C variants are considered as potential genetic risk factors for vaso-occlusive complications in sickle cell disorder (SCD). The purpose of the study was to determine the interaction of the combined haplotypes on the clinical presentations in children with sickle cell disorder.

\section{METHODS}

A cross-sectional study was conducted on 249 children, confirmed for sickle cell disorder. Clinical details and frequencies of clinical episodes in the past one year were noted and a severity index number was allotted to each child and evaluated for their relationship with the combined haplotypes of C677T and A1298C single nucleotide polymorphisms genotyped by real-time PCR.

\section{RESULTS}

The frequency for $677 \mathrm{~T} / 1298 \mathrm{~A}$ haplotype was $46.4 \%$ and that of $677 \mathrm{C} / 1298 \mathrm{C}$ was $12.4 \%$. The three variant combined haplotypes had higher plasma homocysteine values than the wild 677C / 1298A haplotypes ( $\mathrm{P}<0.001)$. Clinical events like vasoocclusive crisis (VOC), homocysteinemia, hospitalization frequency and SI were found significantly related among the children in sickle cell trait (SCT) group (P < 0.001 ) but not so in SCD group. Chances for anemia was 1.93 times more in presence of dual variant alleles (95 \% CI: 0.95 to $3.92, \mathrm{P}=0.07$ ) in SCT. The 677T / 1298C haplotype accounted for higher SI was 7.85 times more than the wild haplotypic children even in SCT children and 1.67 times in SCD children.

\section{CONCLUSIONS}

Presence of the variant haplotypes had significant implication on crisis events in children with sickle cell trait and make them more prone for the clinical severity. A preliminary allelic screening might be helpful in them.

\section{KEY WORDS}

Dual Variant Alleles, Heterozygous, Homozygous, MTHFR, Variant Haplotypes

\author{
Corresponding Author: \\ Dr. Suprava Patel, \\ Department of Biochemistry, \\ All India Institute of Medical \\ Sciences, Raipur, \\ Chhattisgarh, India. \\ E-mail: dr_suprava@yahoo.co.in
}

DOI: $10.14260 / \mathrm{jemds} / 2021 / 390$

How to Cite This Article:

Patel $S$, Nanda $R$, Hussain $N$, et al. Interactions of combined haplotypes of methylenetetrahydrofolate reductase on clinical events in children with sickle cell disorder. J Evolution Med Dent Sci 2021;10(25):1889-1894, DOI: 10.14260/jemds/2021/390

Submission 01-02-2021,

Peer Review 19-04-2021,

Acceptance 28-04-2021,

Published 21-06-2021.

Copyright (C) 2021 Suprava Patel et al. This is an open access article distributed under Creative Commons Attribution License [Attribution 4.0 International (CC BY 4.0)] 


\section{BACKGROUND}

Sickle cell anemia (SCA) is of major public health importance in this region of Central India and is known by its perplexing aspect of varied clinical manifestations. Homocysteinemia induced endothelial dysfunction, platelet activation, activated coagulation cascade are the mainstay pathophysiologies to create a hypercoagulable state resulting in vaso-occlusive phenomenon which is frequently observed in this disorder.1-3 Besides nutritional factors like folic acid or vitamin B12 deficiency, recent studies reported that single nucleotide polymorphisms (SNPs) in enzymes involved in methionine homocysteine metabolism as in methylenetetrahydrofolate reductase (MTHFR) enzyme which maintains the active folate level can lead to homocysteinemia.3,4 Presence of C677T and A1298C SNPs of MTHFR enzyme in SCA have epistatic effects on the clinical presentation in these cases.1,3,5 Co-existence of these SNPs with sickle cell gene can increase the homocysteine levels and thus are regarded as potential genetic risk factors for vaso-occlusive or hemolytic episodes with acute painful events in them. ${ }^{6-8}$ However, very few studies are available regarding the contributory and additive effect of both the polymorphisms towards the clinical complications witnessed in SCA patients in pediatric age group who are most vulnerable for the varied manifestations of the disorder and register a high morbidity and mortality.9,10 Taking into account the above facts, the study was intended primarily to determine the interaction of the combined haplotypes of MTHFR SNPs on the clinical presentations in children diagnosed with sickle cell disorder. To the best of our knowledge, the present study is first of its kind in this region to determine their role as potential genetic risk factors for the vaso-occlusive crisis in them.

\section{METHODS}

The cross-sectional study was conducted after approval from the Institute Ethical Committee. Children of age group 5 to 18 years diagnosed with sickle cell disorder, attending our institute were included for the study. The prevalence of MTHFR SNP ranged from $15-19.3 \%$. Rounding off to $20 \%$ prevalence and using Cochran's formula, $\mathrm{N}=\mathrm{Zpq} / \mathrm{e}^{2}$, the sample size was calculated to be 384 , rounded off to be 350 . But the sample size target could not be achieved and only 249 cases could be enrolled during the study period from March 2017 to March 2019. Total 249 children were enrolled after written informed consent from their parents / legally accepted guardians by convenient sampling method. The study population comprised of 218 HbAS (heterozygous) and 31 HbSS (homozygous) cases as per their high performance liquid chromatography (HPLC) based confirmatory report. The former were grouped as sickle cell trait (SCT) in children and the later as sickle cell disease (SCD). Demographic and clinical details were entered in pre-structured questionnaire used in our institute. Clinical history of past one year was noted for all the children for frequencies of vaso-occlusive crisis (VOC) or acute hemolytic crisis, acute painful events, infective episodes, blood transfusions and hospitalization. Severity Index (SI) number was allotted to each child by summing up the number of past and present events as described above. The children were subcategorized as those with a SI of $\leq 6$ and those with $>$ 6 for comparison among the study groups. Blood hemoglobin and plasma homocysteine were evaluated after enrollment to know the status of anemia and homocysteinemia.

Once enrolled, $3 \mathrm{ml}$ of blood was collected in ethylenediaminetetraacetic acid (EDTA) vacutainer and transported to laboratory in chiller box. Hemoglobin $(\mathrm{Hb})$ was measured in XP - 100 Fully Automated hematology Analyzer, Sysmex. $500 \mu \mathrm{l}$ blood was aliquoted and stored at $4^{\circ}$ to $8^{\circ} \mathrm{C}$ for deoxyribonucleic acid (DNA) extraction using Invitrogen ${ }^{\mathrm{TM}}$ PureLink $^{\mathrm{TM}}$ Genomic DNA Mini kit from ThermoFisher Scientific on weekly basis. Extracted DNA was stored at $-80^{\circ} \mathrm{C}$ until processed for real-time polymerase chain reaction (PCR). Remaining blood was centrifuged for plasma separation which was aliquoted and stored in $-80^{\circ} \mathrm{C}$ to be analyzed later for plasma homocysteine (Hcy) in Advia Centaur XP Fully Automated Chemiluminescence Immunoanalyzer, Seimens.

The MTHFR polymorphisms under study were genotyped for C677T (rs1801133) and A1298C (rs1801131) (Assay ID's C_1202883_20 and C_850486_20 respectively) using TaqMan SNP Genotyping PCR Kit from Applied Biosystems, ThermoFisher. PCR was processed in CFX96 real time PCR system, Biorad. The $\mathrm{C} 677$ allele of $\mathrm{C} 677 \mathrm{~T}$ was considered as the wild allele and $\mathrm{T} 677$ allele as the variant allele whereas for A1298C, allele A1298 was considered as wild and allele C1298 as the variant allele. As both SNPs has C alleles, to avoid the confusion for the readers, the variant allele of A1298C will be presented as $\mathrm{C}^{\prime}$ and the wild allele of $\mathrm{C677T}$ as $\mathrm{C}$ in the manuscript henceforth.

Combined haplotypes, 677C / 1298A, 677C / 1298C', 677T / 1298A and 677T / 1298C', each comprising of either of the alleles of the MTHFR variants were evaluated for their combined effect on the clinical variables. 677C / 1298A consisting of both the wild alleles was considered as wild haplotype. The other haplotypes comprising of at least one variant allele of either SNPs were considered as variant haplotypes. 677T / 1298C' combined haplotype with both variant alleles was noted as the dual variant haplotype. The allelic and haplotypic frequency percentages were calculated from the total allelic population which was considered as $\mathrm{N} * 2$ $(249 * 2)=498$.

Children with blood $\mathrm{Hb}$ level $\leq 11 \mathrm{gm} / \mathrm{dL}$ were considered under clinical variables for anemia.11,12 The cut off value for plasma Hcy was $13 \mu \mathrm{mol} / \mathrm{L}$ (as per kit insert) beyond which it was considered homocysteinemia.

\section{Ethical Statement}

This research was reviewed and approved by the Institutional Ethical Committee of All India Institute of Medical Sciences, Raipur, Chhattisgarh, India. Informed consent was obtained from all participants.

\section{Statistical Analysis}

All statistical calculations were computed in IBM ${ }^{\circledR}$ SPSS version 20. Haplotypic frequency was presented as percentage and the quantitative variables were presented as mean with standard deviation (SD). Chi-Square test was applied for distribution of the combined haplotypes among the groups. Comparison of the quantitative variables among the haplotypes in the study population was extrapolated using independent $\mathrm{t}$ - test. Further analysis by logistic regression along with odd ratio (OR) and $95 \%$ confidence interval (CI) was performed to predict the relationship between the haplotypic variants with the clinical outcomes. P - value $<0.05$ 
was accepted for statistical significance in this study. Allelic population of 498 was considered for performing the statistical analysis. For all comparisons, the wild haplotypic (677C / 1298A) children were considered as the reference category.

\section{RESULTS}

\section{Characteristics of the Study Population and the} Haplotypic Distribution

The study population consisted $87.6 \%(\mathrm{~N}=218)$ SCT and $12.4 \%(\mathrm{~N}=31)$ SCD children of 5 to 18 years age group. The mean (SD) age of the children was 11.27 (3.47) years and comprised of 137 (13.8\%) female and 112 (11.2\%) male children. The overall frequency percentages of clinical events, including both present and past history, in the study population are depicted in Figure - 1. Homocysteinemia and anemia were prevalent with $71.9 \%$ and $65.5 \%$ of the allelic population at the time of enrollment. The episodes of VOC, painful events, infections and hospitalization ranged from 20 $\%$ to $40 \%$. Only $4 \%$ of these children gave history of blood transfusions. $11.2 \%$ children of the total allelic population documented $\mathrm{SI}>6$.

The distribution of the combined haplotypes in the study population outlined in Table 1, was merely different between the study groups $(\mathrm{P}=0.05)$. The frequency percentages of variant alleles T677 and C'1298 were $15.1 \%$ and $44.4 \%$ respectively. The odds for dual variant haplotype $677 \mathrm{~T} /$ $1298 C^{\prime}$ was 2.52 times (95 \%CI: 1.13 to $5.5, \mathrm{P}=0.008$ ) in the SCD group when compared to the reference haplotype.

\section{Comparison of Quantitative Variables within the Haplotypic Variants}

The comparison of the quantitative variables among the four haplotypes is illustrated in Figure 2. Children with 677T / 1298C' haplotype documented significantly lower body mass index (BMI) $(\mathrm{P}=0.015)$ and Hb levels $(\mathrm{P}=0.006)$ when compared to children with 677C / 1298A haplotype. The three variant combined haplotypes had higher plasma homocysteine values than the wild haplotypes $(\mathrm{P}<0.001)$

\section{Regression Analysis of Combined Haplotypes and the Clinical Variables in SCT Children \\ Inter - relationship of MTHFR combined haplotypes with the clinical events in SCT group was analyzed using logistic regression analysis and is delineated in Table 2 . Clinical events like VOC, infective episodes, homocysteinemia, hospitalization frequency and SI were found significantly related among the groups ( $\mathrm{P}<0.001) .25 .5 \%$ of SCT children who documented history of frequent VOC events, were reported for 677T / $1298 C^{\prime}$ in SNP genotyping as against only $7.4 \%$ with no VOC events.}

The odds for vascular crisis in dual variant haplotypes was 3.79 times (CI $95 \%$ : 1.99 to $7.24, \mathrm{P}<0.001$ ) more than the reference category in SCT children. Co-existence of dual variant alleles raised the chances for painful episodes by $59 \%$ and anemia by 1.93 times. The prediction for severe grade anemia $(\mathrm{Hb}<7 \mathrm{gm} / \mathrm{dl})$ was found to be increased by $42 \%$ in SCT children (95\% CI: 0.29 to $5.48, \mathrm{P}=0.61$ ) in these haplotypes (data not shown).

Similarly, the variant haplotypes revealed significant relationship with homocysteinemia and hospitalization frequency $(\mathrm{P}<0.001)$. All children with 677T / 1298C' haplotype had homocysteinemia at the time of enrollment. The odds for frequent hospitalizations ( $>2$ times a year) was greatly influenced (49.79 times) in variants even though they are traits for the disease (data not shown). Similarly, the likelihood for frequent blood transfusions was increased by 42 $\%$ in C677T / 1298C'. Presence of dual variant alleles rendered these children towards higher SI score (7.85 times) than the reference haplotypes.

\section{Regression Analysis of Combined Haplotypes and the Clinical Variables in SCD Children}

As delineated in Table 3, the regression analysis of the MTHFR combined haplotypes depicted no significant relationship with the clinical events in SCD children. $100 \%$ of the $677 \mathrm{~T} / 1298 \mathrm{C}^{\prime}$ $(\mathrm{N}=12)$ haplotypes of this group depicted anemia and homocysteinemia at the time of enrollment. The odds for blood transfusion was 4.5 times (CI $95 \%$ : $0.68-29.81, \mathrm{P}=0.12$ ) in these haplotypes as against the reference group. The chances for a higher SI score were more by $67 \%$ in children with dual variant alleles.

\begin{tabular}{|c|c|c|c|}
\hline & $\begin{array}{c}\text { SCT Allele } \\
N=436 \\
N(\%)^{\wedge}\end{array}$ & $\begin{array}{c}\text { SCD Allele } \\
\mathrm{N}=62 \\
\mathrm{~N}(\%)^{\wedge}\end{array}$ & $\chi^{2}$ df, P - Value \\
\hline $\begin{array}{l}677 \mathrm{C} / 1298 \mathrm{~A} \\
231(46.4 \%)\end{array}$ & $211(48.4)$ & $20(32.3)$ & \multirow{4}{*}{$7.93_{3}, 0.05$} \\
\hline $\begin{array}{l}677 C / 1298 C^{\prime} \\
127(25.5 \%)\end{array}$ & $111(25.5)$ & $16(25.8)$ & \\
\hline $\begin{array}{l}677 \mathrm{~T} / 1298 \mathrm{~A} \\
78(15.7 \%)\end{array}$ & $64(14.7)$ & $14(22.6)$ & \\
\hline $\begin{array}{l}677 \mathrm{~T} / 1298 \mathrm{C}^{\prime} \\
62(12.4 \%)\end{array}$ & $50(11.5)$ & $12(19.4)$ & \\
\hline \multicolumn{4}{|c|}{$\begin{array}{c}\text { Table 1. Distribution of the Combined Haplotypes of C677T and } \\
\text { A1298C MTHFR SNPS within the Study Population }\end{array}$} \\
\hline
\end{tabular}

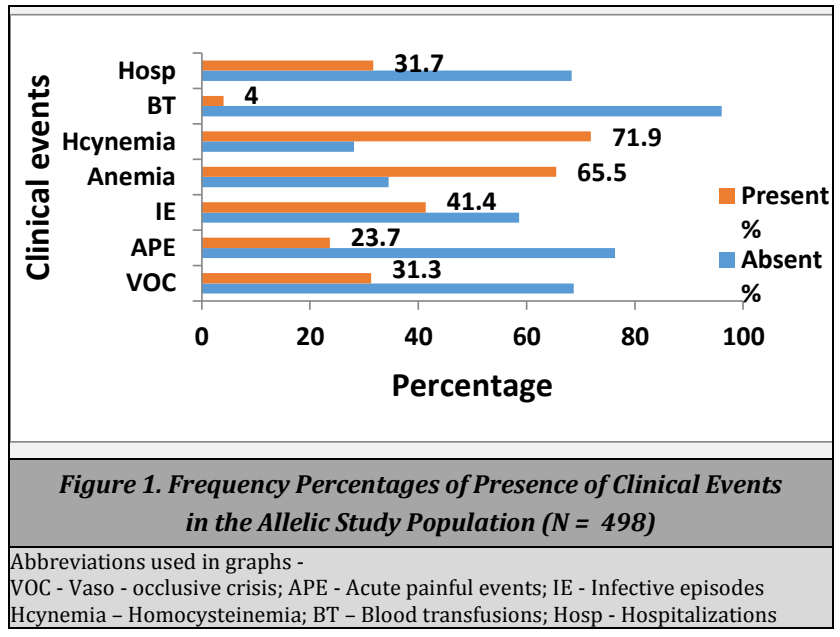




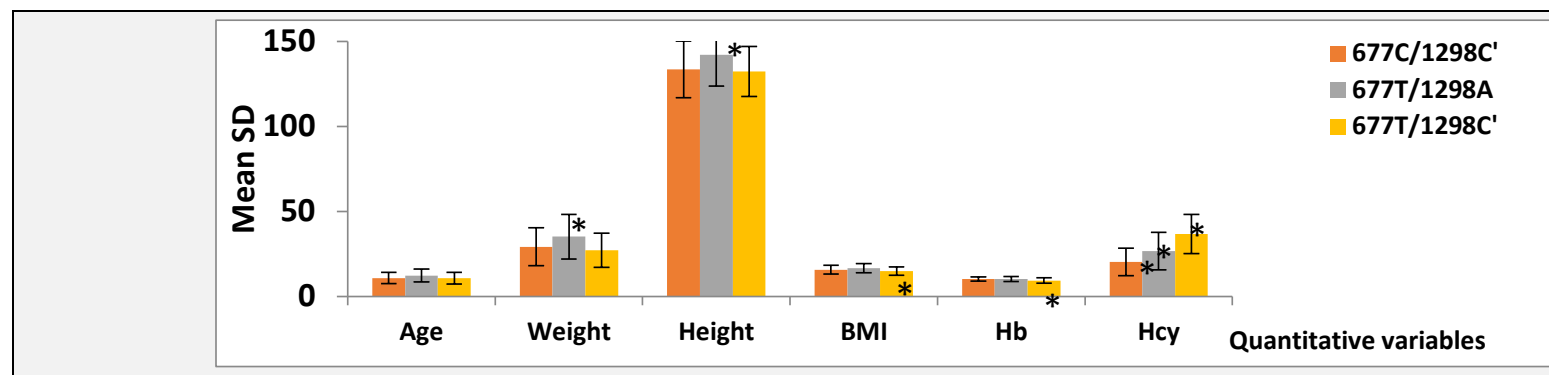

Figure 2. Comparison of Mean(SD) of Quantitative Variables among the Four Combined Haplotypes of MTHFR ( $N=498$ and df = 497) *Significant at $\mathrm{P}<0.05$ when compared to the wild combined haplotype 677C / 1298A

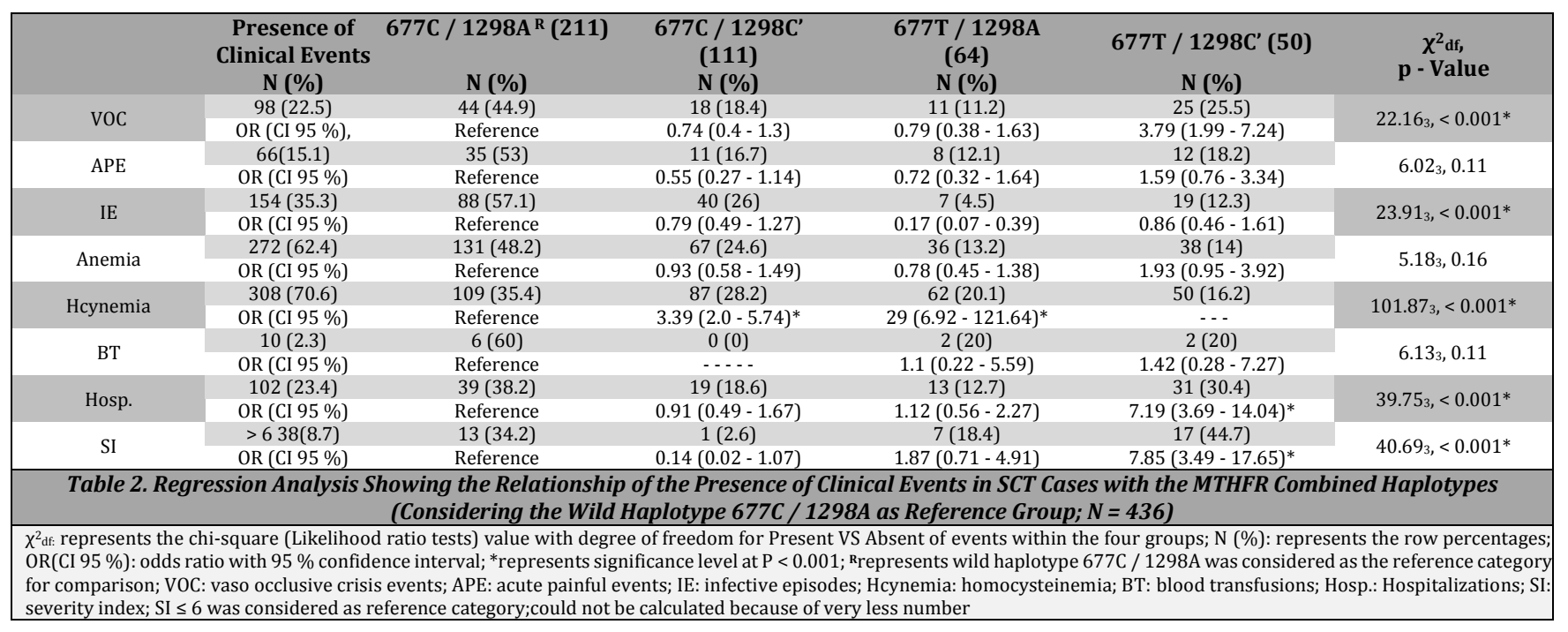

\begin{tabular}{|c|c|c|c|c|c|c|}
\hline & $\begin{array}{c}\text { Presence of } \\
\text { Clinical Events } \\
\text { N (\%) }\end{array}$ & $\begin{array}{c}677 C / 1298 A^{R} \\
(20) \\
N(\%)\end{array}$ & $\begin{array}{c}677 \mathrm{C} / 1298 C^{\prime} \\
(16) \\
\mathrm{N}(\%)\end{array}$ & $\begin{array}{c}\text { 677T / 1298A } \\
(14) \\
N(\%)\end{array}$ & $\begin{array}{c}\text { 677T / 1298C' (12) } \\
\text { N (\%) }\end{array}$ & $\chi^{2} \mathrm{df}, \mathrm{p}$ - Value \\
\hline \multirow{2}{*}{ VOC } & $58(93.5)$ & $19(32.8)$ & $15(25.9)$ & $13(22.4)$ & $11(19)$ & \multirow{2}{*}{$0.15_{3}, 0.98$} \\
\hline & OR (CI $95 \%)$ & Reference & $0.79(0.05-13.69)$ & $0.68(0.04-11.95)$ & $0.58(0.03-10.21)$ & \\
\hline \multirow{2}{*}{ APE } & $52(83.9)$ & $17(32.7)$ & $13(25)$ & $12(23.1)$ & $10(19.2)$ & \multirow{2}{*}{$0.143,0.99$} \\
\hline & OR (CI $95 \%)$ & Reference & $0.77(0.13-4.43)$ & $1.06(0.15-7.34)$ & $0.88(0.13-6.22)$ & \\
\hline \multirow{2}{*}{ IE } & $52(83.9)$ & $16(30.8)$ & $14(26.9)$ & $14(26.9)$ & $8(15.4)$ & \multirow{2}{*}{$7.44_{3}, 0.06$} \\
\hline & OR (CI $95 \%)$ & Reference & $1.75(0.28-11.05)$ & $\ldots$ & $0.5(0.09-2.54)$ & \\
\hline \multirow{2}{*}{ Anemia } & $54(87.1)$ & $17(31.5)$ & $12(22.2)$ & $13(24.1)$ & $12(22.2)$ & \multirow{2}{*}{$3.85_{3}, 0.28$} \\
\hline & OR (CI $95 \%)$ & Reference & $0.77(0.13-4.43)$ & $1.06(0.15-7.34)$ & - . . - & \\
\hline \multirow{2}{*}{ Hcynemia } & $50(80.6)$ & $14(28)$ & $12(24)$ & $12(24)$ & $12(24)$ & \multirow{2}{*}{$7.01_{3}, 0.07$} \\
\hline & OR (CI $95 \%)$ & Reference & $1.29(0.29-5.66)$ & $2.57(0.44-15.19)$ & $\ldots$ & \\
\hline \multirow{2}{*}{ BT } & $10(16.1)$ & $2(20)$ & $2(20)$ & $2(20)$ & $4(40)$ & \multirow{2}{*}{$2.96_{3}, 0.39$} \\
\hline & OR (CI $95 \%)$ & Reference & $1.29(0.16-10.29)$ & $1.5(0.19-12.15)$ & $4.5(0.68-29.81)$ & \\
\hline \multirow{2}{*}{ Hosp. } & $56(90.3)$ & $16(28.6)$ & $14(25)$ & $14(25)$ & $12(21.4)$ & \multirow[t]{2}{*}{$7.35_{3}, 0.06$} \\
\hline & OR (CI $95 \%)$ & Reference & $1.75(0.28-11.05)$ & $\ldots$ & $\ldots$ & \\
\hline \multirow{3}{*}{ SI } & $\leq 6^{R}$ & $14(31.8)$ & $12(27.3)$ & $11(25)$ & $7(15.9)$ & \multirow[t]{3}{*}{$1.42_{3}, 0.7$} \\
\hline & $>618(30.6)$ & $6(33.3)$ & $4(22.2)$ & $3(16.7)$ & $5(27.8)$ & \\
\hline & OR (CI $95 \%)$ & Reference & $0.78(0.18-3.42)$ & $0.64(0.13-3.14)$ & $1.67(0.37-7.24)$ & \\
\hline \multicolumn{7}{|c|}{ Table 3. Regression Analysis Showing the Relationship of MTHFR Combined Haplotypes with the Clinical Events in SCD Cases (N = 62) } \\
\hline
\end{tabular}

\section{DISCUSSION}

Vascular complications greatly influence the morbidity in children with sickle cell disorder even after regular folic acid supplementation, especially in homozygous SCD cases. Coexistence of any other polymorphism, like MTHFR polymorphism that impairs folic acid utilization leading to homocysteinemia would further complicate the scenario, even in heterozygous subjects. Considering the facts, the study was planned to evaluate the impact of the MTHFR haplotypes on the clinical outcomes in children with sickle cell disorder. The cross-sectional study included 249 children with confirmed diagnosis of sickle cell disorder, out of which $87.6 \%$ were heterozygous SCT and $12.4 \%$ were homozygous SCD.

Few studies in various geographical locations sketched varied prevalence data for each of the variant alleles, but not much for the dual polymorphisms to compare with. The T677 allele frequency varied from $57.3 \%$ in Central India, $0.03 \%$ in Western India and $13 \%$ in North India.5,13,14 The overall T677 allele frequency was $15.1 \%$ in our study population which was comparable to Pandey et al. ${ }^{5}$ The frequency of C'1298 was reported $15 \%$ in Lagos, Nigeria and $40.9 \%$ in Brasilian population. 3,15 Present study recorded $44.4 \%$ prevalence of C'1298. Interaction of genetic and environmental factor might play a role in the varied distribution of these polymorphisms 
in different regions. The distribution of the four combined haplotype between the groups did show some significant association $(\mathrm{P}=0.05)$ depicting higher prevalence of $677 \mathrm{~T} /$ $1298 C^{\prime}$ in SCD group (19.4 \%) than SCT cases (11.5\%) (Table 1). The overall prevalence of dual variant haplotypes was 12.4 $\%$ that accorded to the noted prevalence of $9.1 \%$ to $15.2 \%$ in Hatzlhofer et al. study in 277 HbSS cases. ${ }^{15}$

Presence of the MTHFR variants also highly influenced the rise in plasma homocysteine level and frequency of hospitalization $(\mathrm{P}<0.001)$. Various articles have reflected that repeated events of vaso-occlusive phenomenon leading to frequent hemolytic and painful crisis result in frequent hospitalization. These events often perpetuate towards higher incidences of morbidity like impaired growth, anemia in pediatric age group that also explains the lower BMI $(\mathrm{P}=$ $0.015)$ and blood hemoglobin $(P=0.006)$ in these children (Figure - 2).10,16,17 Homocystenemia is often focused in clinical conditions associated with vascular and thrombotic events which is considered a common phenomenon in homozygous SCD cases. ${ }^{4,18-20}$ However, presence of both the variant alleles, T677 and C'1298 documented significant influence on VOC, homocysteinemia and frequency of hospitalization in SCT group (Table - 2). Hatzlhofer et al. study reported $15.2 \%$ prevalence of double mutant 677T / 1298C' haplotype in VOC cases as against $9.1 \%$ in cases without vascular events $(\mathrm{P}=$ 0.192) and predicted $T$ allele as a potential risk allele for vascular complications in HbSS cases $(\mathrm{P}=0.015)$ when compared to $C^{\prime}$ allele $(\mathrm{P}=0.913) \cdot{ }^{15}$ Similarly, other studies also predicted $\mathrm{T}$ allele as a risk factor for vaso-occlusive phenomenon seen in SCD cases.1,13,21 Similar to these studies, our study indicated that coexistence of dual mutant alleles in children significantly increased the risk of VOC by 3.79 times than the wild group (Table - 2) even in trait group. On further analysis, it was observed that $50 \%$ of the children who documented vascular crisis more than two times in that year were 677T / 1298C' haplotypes (data not shown). The resultant effect of frequent vascular complications might have implicated for higher frequency of painful crisis (by $59 \%$ ), hospitalization (7.19 times, $\mathrm{P}<0.001$ ) and blood transfusions (1.42 times, $\mathrm{P}=0.67$ ) observed in SCT children. Eventually these children tend to have higher severity index ( 7.85 times) than the wild haplotypes (Table - 2) although the combined haplotypes failed to reveal significant relationship with the clinical events in SCD group.

The dual variant haplotypes were more prone for blood transfusions and $100 \%$ of them documented severe grade of anemia, homocysteinemia and frequent hospitalization (Table - 3). This could be attributed to the fact that the said mutations reduce the enzyme activity to $30 \%$ and $70 \%$ for homozygous C'1298 and T677 respectively. ${ }^{22,23}$ Thus, presence of dual variant alleles might have additive effect for reduced enzyme activity leading to significant homocysteinemia. Further studies in the variant haplotypes might add valuable insight regarding the additive effects of reduced enzyme activity. Raised plasma homocysteine is implicated for endothelial dysfunction and an impending cause for thrombosis leading to vaso-occlusive events. ${ }^{2,3,8,18}$ Hence, presence of variant alleles predisposes for higher SI in children ascertained by summing up of the frequency of the clinical events. ${ }^{11,24}$ In agreement to the fact, both the SCT as well as SCD children depicted higher probability of SI > 6 in 677T / 1298C' haplotypes (Table $2 \& 3$ ). Inspite of folic acid supplementation in these children, elevated plasma homocysteine indicated that the dose needs to be modified to meet the demand of folic acid and vitamin
B12 in children with mutant haplotypes of C677T / 1298C' or may be active folate, $\mathrm{L}$ - methyl folate that needs to be added. ${ }^{25-}$ ${ }^{27}$ Few studies documented raised homocysteine levels in SCA cases inspite of FA supplementation and explained significant contributory effect of variant allele with B12 deficiency and homocysteinemia $(\mathrm{P}<0.001) \cdot{ }^{28-30}$ Present study reflected implication of dual variant alleles on anemia with an odds of 2.34 times (CI $95 \%: 1.18-4.64, \mathrm{P}=0.015$ ) in the study population (data not shown). Various other studies also related MTHFR mutation to anemia and thus predicted these genetic polymorphisms towards abnormal indices pertaining to megaloblastic anemia which is again not uncommon in children with sickle cell disorder even after folate supplementation. ${ }^{30-32}$

\section{CONCLUSIONS}

Coexistence of both variant alleles of MTHFR C677T and A1298C' posses significant implication on vaso-occlusive events and frequency of hospitalization in children with SCA, especially in SCT children, that renders increased vulnerability towards higher severity index by $7-8$ times. A preliminary allelic screening might be helpful in identifying the high risk children.

A substantial dose modification should be considered for these children with copresence of variant alleles. Accordingly, folic acid and vitamin B12 supplementations can be modified to control homocysteine levels and thus reduce the frequency of crisis events.

An active form of folate might be beneficial for these groups of children instead of regular folic acid supplementation. However, further large scale studies are still required to accurately evaluate the association of these two MTHFR polymorphisms with the complications of sickle cell disorder.

\section{Study Limitations}

The major limitations of this study reside in the fact that it was a hospital based study and quantitative evaluation of plasma folate and vitamin B12 was not undertaken due to fund constraint. Blood hemoglobin and plasma homocysteine reflected the levels at the time of admission as previous reports were found missing or not available in most cases at the time of enrollment. Further large scale studies in community level including the quantitative evaluation of blood parameters might provide more accurate information regarding the risk association. Quantification of these values in children without sickle cell disorder would have provided a more defined comparison of the plasma levels between cases and control. However, this study intended to determine the effect of SNPs on clinical variables, the severity index to be more precise, between the cases and not just mere comparison of the quantitative variables.

Data sharing statement provided by the authors is available with the full text of this article at jemds.com.

Financial or other competing interests: Authors received funds by Chhattisgarh Council of Science and Technology, Raipur, Chhattisgarh, India.

Disclosure forms provided by the authors are available with the full text of this article at jemds.com. 
Author Contributions - Conceptualization: S. Patel, P.K. Patra; Methodology: S. Patel, N. Hussain; Formal analysis: S. Patel, R. Nanda; Investigation: N. Hussain, E. Mohapatra; Resources: S. Patel, E. Mohapatra, P.K. Patra; Data curation: S. Patel, N. Hussain, P.K. Patra; Writing: Original draft: S. Patel, R. Nanda; Writing - Review \& Editing: E. Mohapatra, P.K. Patra; Visualization: R. Nanda, N. Hussain; Supervision: S. Patel, N. Hussain; Project administration: S. Patel, P.K. Patra. Funding acquisition: S. Patel

\section{REFERENCES}

[1] Neto FM, Lourenço DM, Noguti MAE, et al. The clinical impact of MTHFR polymorphism on the vascular complications of sickle cell disease. Braz J Med Biol Res 2006;39(10):1291-5.

[2] Pandey S, Pandey HR, Mishra RM, et al. Increased homocysteine level in indian sickle cell anemia patients. Indian J Clin Biochem 2012;27(1):103-4.

[3] Adelekan 00, Uche EI, Balogun TM, et al. Methylene tetrahydrofolate reductase gene mutation in sickle cell anaemia patients in Lagos, Nigeria. Pan Afr Med J 2019;34:213.

[4] Meher S, Patel S, Das K, et al. Association of plasma homocysteine level with vaso-occlusive crisis in sickle cell anemia patients of Odisha, India. Ann Hematol 2019;98(10):2257-65.

[5] Pandey SK, Meena A, Kishor K, et al. Prevalence of factor V Leiden G1691A, MTHFR C677T and prothrombin G20210A among Asian Indian sickle cell patients. Clin Appl Thromb Hemost 2012;18(3):320-3.

[6] Vasisht S, Gulati R, Narang R, et al. Polymorphism (C677T) in the 5,10-methylenetetrahydrofolate reductase (MTHFR) gene: a preliminary study on north Indian men. Indian J Clin Biochem 2002;17(1):99-107.

[7] Naik RP, Streiff MB, Haywood C, et al. Venous thromboembolism in adults with sickle cell disease: a serious and under-recognized complication. Am J Med 2013;126(5):443-9.

[8] Hebbel RP. Ischemia-reperfusion injury in sickle cell anemia: relationship to acute chest syndrome, endothelial dysfunction, arterial vasculopathy and inflammatory pain. Hematol Oncol Clin North Am 2014;28(2):181-98.

[9] Panigrahi S, Patra PK, Khodiar PK. The Screening and morbidity pattern of sickle cell anemia in Chhattisgarh. Indian J Hematol Blood Transfus 2015;31(1):104-9.

[10] Jain D, Bagul AS, Shah M, et al. Morbidity pattern in hospitalized under five children with sickle cell disease. Indian J Med Res 2013;138(3):317-21.

[11] El-Hazmi MA. Clinical and haematological diversity of sickle cell disease in Saudi children. J Trop Pediatr 1992;38(3):106-12.

[12] Hu Z, Chang SM, Younis R, et al. Optimal hemoglobin level for pediatric sickle cell patients who undergo adenotonsillectomy. Blood 2018;132(Suppl 1):4938.

[13] Nishank SS, Singh MPSS, Yadav R. Clinical impact of factor V Leiden, prothrombin G20210A and MTHFR C677T mutations among sickle cell disease patients of Central India. Eur J Haematol 2013;91(5):462-6.

[14] Kangne HK, Jijina FF, Italia YM, et al. The Prevalence of factor V Leiden (G1691A) and methylenetetrahydrofolate reductase $\mathrm{C} 677 \mathrm{~T}$ mutations in sickle cell disease in
Western India. Clin Appl Thromb Hemost 2015;21(2):186-9.

[15] Hatzlhofer BLD, Bezerra MAC, Santos MNN, et al. MTHFR polymorphic variant $\mathrm{C} 677 \mathrm{~T}$ is associated to vascular complications in sickle-cell disease. Genet Test Mol Biomarkers 2012;16(9):1038-43.

[16] Serjeant GR, Ghosh K, Patel J. Sickle cell disease in India: a perspective. Indian J Med Res 2016;143(1):21-4.

[17] Dash BP, Das RK. Age, sex and seasonal variations of sickle cell disorder cases in Orissa. J Hum Ecol 1998;9(3):281-4.

[18] Uche E, Adelekan 0, Akinbami A, et al. Serum homocysteine and disease severity in sickle cell anemia patients in Lagos. J Blood Med 2019;10:127-34.

[19] Whitehead VM. Acquired and inherited disorders of cobalamin and folate in children. $\mathrm{Br} \mathrm{J}$ Haematol 2006;134(2):125-36.Carmel R, Green R, Rosenblatt DS, et al. Update on cobalamin, folate and homocysteine. Hematol Am Soc Hematol Educ Program 2003:62-81.

[20] Kutlar A, Kutlar F, Turker I, et al. The methylene tetrahydrofolate reductase (C677T) mutation as potential risk factor for avascular necrosis in sickle cell disease. Hemoglobin 2001;25(2):213-7.

[21] Wan L, Li Y, Zhang Z, et al. Methylenetetrahydrofolate reductase and psychiatric diseases. Transl Psychiatry 2018;8(1):1-12.

[22] Castiglia P, Sanna V, Azara A, et al. Methylenetetrahydrofolate reductase (MTHFR) C677T and A1298C polymorphisms in breast cancer: a sardinian preliminary case-control study. Int J Med Sci 2019;16(8):1089-95.

[23] Al-Saqladi AWM, Harper G, Delpisheh A, et al. Frequency of the MTHFR C677T polymorphism in Yemeni children with sickle cell disease. Hemoglobin 2010;34(1):67-77.

[24] Patel S, Bhaumik S. Sickle cell disease and folate supplementation. Panacea J Med Sci 2019;9(2):39-42.

[25] Verhoef H, Veenemans J, Mwangi MN, et al. Safety and benefits of interventions to increase folate status in malaria-endemic areas. Br J Haematol 2017;177(6):90518.

[26] Shelton RC, Manning JS, Barrentine LW, et al. Assessing effects of l-methylfolate in depression management: results of a real-world patient experience trial. Prim Care Companion CNS Disord 2013;15(4):PCC.13m01520.

[27] Lowenthal EA, Mayo MS, Cornwell PE, et al. Homocysteine elevation in sickle cell disease. J Am Coll Nutr 2000;19(5):608-12.

[28] FP Van Der Dijs, Schnog JJ, Brouwer DA, et al. Elevated homocysteine levels indicate suboptimal folate status in pediatric sickle cell patients. Am J Hematol 1998;59(3):192-8.

[29] Zittan E, Preis M, Asmir I, et al. High frequency of vitamin B12 deficiency in asymptomatic individuals homozygous to MTHFR C677T mutation is associated with endothelial dysfunction and homocysteinemia. Am J Physiol Heart Circ Physiol 2007;293(1):H860-5.

[30] Al-Yassin A, Osei A, Rees D. Folic acid supplementation in children with sickle cell disease. Arch Dis Child 2012;97(Suppl 1):A91-2.

[31] Dixit R, Nettem S, Madan SS, et al. Folate supplementation in people with sickle cell disease. Cochrane Database Syst Rev 2016;3(3):CD011130. 